\title{
Onkeno: género y el surgimento de los caciques korubo en el valle del Yavarí
}

\section{Juliana Oliveira Silva}

(iD) https://orcid.org/0000-0002-9744-1843

Museo Nacional/ Universidad Federal de Río de Janeiro, Brasil anailujoliveiras@gmail.com

RESUMEN

Este artículo examina la manera como la noción de "cacique», traída por el contacto interétnico, viene siendo apropiada por los korubo, hablantes de la familia lingüistica pano y habitantes de la Tierra Indigena Valle del Yavarí, estado de Amazonas, en la Amazonía brasileña. A partir de una primera investigación etnográfica realizada entre los korubo, aborda algunas transformaciones en las relaciones de género, impulsadas por el contacto interétnico con el Estado brasileño y las instituciones indigenistas. En esta relación, hay un equívoco entre la concepción no indígena de «cacique» y determinadas figuras de autoridad en el cotidiano de las aldeas korubo.

Palabras clave: género, cacique, korubo, contacto, FUNAI.

\section{Onkeno: gender and the emergence of Korubo caciques in the Yaravi Valley}

ABSTRACT

This article examines how the notion of «cacique», introduced through interethnic contact, has been appropriated by the Korubo, speakers of the Pano linguistic family and inhabitants of the Vale do Javari Indigenous Territory, state of Amazonas, in the Brazilian Amazon. Based on the first ethnographic research carried out among the Korubo, it investigates transformations in gender relations 
that were driven by the interethnic contact with the Brazilian State and indigenous agencies. The article argues that, in the context of this relationship, there is a misunderstanding between the non-indigenous concept of "cacique» and certain authority figures in the daily life of Korubo villages.

Keywords: gender, cacique, Korubo, contact, FUNAI. 
Era noviembre de 2018 cuando, sin saberlo, conocí al que sería uno de los caciques korubo. Él estaba participando de una actividad en el Museu do Índio (MI/FUNAI), en Río de Janeiro y, en ese momento, no se presentó como cacique ${ }^{1}$. Simplemente me dijo que su nombre era Malevo y que estaba acompañado por un joven korubo llamado Takvan Vakwë. Ambos colaboraban como becarios en un proyecto de documentación de lenguas indígenas para la construcción del primer diccionario de la lengua korubo.

En ese momento, la Coordenação-Geral de Índios Isolados e de Recente Contato de la Fundação Nacional do Índio (CGIIRC/FUNAI) ya me había pedido que realizara la primera investigación de campo, de carácter antropológico, entre los korubo, uno de los siete pueblos que habitan en la Tierra Indígena Valle del Yavarí, Amazonas. La CGIIRC/FUNAI argumentó que carecía de información etnográfica para subvencionar la planificación y ejecución de la política indígena para este pueblo. Hasta entonces, además de los agentes estatales, solo un lingüista había estado con los korubo (Oliveira, 2009). Sabíamos que pertenecen a la rama septentrional de la familia lingüística pano.

Actualmente, mientras una parte de los korubo se encuentra en situación de aislamiento, la mayoría de ellos son considerados por el Estado brasileño como de «contacto reciente», es decir, están continuamente relacionados con instituciones indigenistas: FUNAI y la Secretaria Especial de Saúde Indígena - SESAI. Hasta el año 2020, esta población korubo de contacto reciente ascendía a 127 personas; de estas, 93 vivían en cuatro aldeas del río Ituí y otras 34 estaban ubicadas en el río Coari.

Durante nuestro primer encuentro, que tuvo lugar en noviembre de 2018, en Río de Janeiro, no escuché la palabra «cacique» en referencia a ninguno de

«Cacique» es una palabra de origen arawak que comenzó a circular entre las poblaciones amerindias desde el período colonial, utilizada por los funcionarios del gobierno para designar a quienes reconocían como autoridades en un determinado grupo. 
los korubo. En esa ciudad, Malevo y Takvan Vakwë utilizaban esta palabra en bromas con personas no indígenas que les compraban/pagaban algo, y que los llevaban a pasear por la ciudad. En contraste, el término «cacique» era utilizado con mayor seriedad por los no indígenas en diálogos con los korubo, como ocurrió en MI/FUNAI.

En un intento por convencer a Malevo y Takvan Vakwë para que autoricen una grabación de imágenes, un funcionario de MI/FUNAI argumentó que el entonces director, el «cacique del Museo», había solicitado un registro audiovisual de un relato de su experiencia en Río de Janeiro. Era la primera vez que los dos korubo estaban en esta ciudad. Sin embargo, argumentar que la solicitud había sido realizada por el «cacique del Museo» no fue suficiente para convencerlos de autorizar la grabación de imágenes. Los korubo seguían siendo reacios a las grabaciones audiovisuales.

Solo tres meses después escuché que la palabra «cacique» era utilizada para referirse a un korubo. En febrero de 2019, conocí a otro hombre korubo en la oficina del Frente de Proteção Etnoambiental Vale do Javari (FPEVJ/FUNAI) en Tabatinga, Amazonas. Esta vez, fui presentada por la FPEVJ/FUNAI al «cacique Txitxopi», quien estaba acompañado por Malevo y Takvan Vakwë, este último su hermano menor. Ambos tradujeron las conversaciones de Txitxopi con los no indígenas, ya que este no hablaba portugués.

Los tres korubo estaban en Tabatinga para hacer compras y, cuando regresaran a sus aldeas, me llevarían con ellos. Sería la primera vez que conocería las aldeas korubo en el río Ituí. Esa mañana, Takvan Vakwë sugirió a la FUNAI que me llevaran al lugar donde se alojaban para «hacer reunión» ("fazer reunião") a las cuatro de la tarde, cuyo objetivo era aclarar el rumbo de mi trabajo como antropóloga y docente en las aldeas korubo del río Ituí.

Hace unos años, los korubo exigieron de la FUNAI el aprendizaje del idioma portugués, de conocimientos numéricos para calcular el dinero, y la comprensión de las «cosas de los nawa» ("coisas de nawa"; nawa: no indígenas) (Oliveira, 2016, p. 1). En este tipo de reclamos, hechos por los korubo a las instituciones estatales, la figura de Txitxopi como «cacique» parecía adquirir centralidad. La FUNAI lo llamaba de esta manera, y los korubo incluso se divertían con el uso de esa nueva palabra. Sin embargo, al convivir en las aldeas korubo, me di cuenta de que, en ausencia de personas no indígenas, el cargo de cacique prácticamente desaparecía, mientras se vislumbraban otras formas de autoridad, como la de las mujeres mayores, llamadas matxo. 
Entre enero de 2019 y marzo de 2020, conviví con los korubo en diferentes contextos: (i) en las aldeas korubo del río Ituí; (ii) en la Base de Proteção Etnoambiental (BAPE/FUNAI), ubicada en la confluencia de los ríos Ituí y Itaquaí, en la Tierra Indígena Valle del Yavarí, Amazonas, y (iii) en ciudades como Río de Janeiro, Tabatinga y Benjamin Constant, Amazonas ${ }^{2}$. Durante ese período de trabajo de campo, los korubo no mencionaron si en el pasado, existían, o no, jefes entre ellos.

En la vida cotidiana de los korubo, los temas recurrentes eran las relaciones con los nawa, sus saberes y tecnologías, los objetos y bienes industrializados a los que comenzaron a acceder a través del contacto permanente con el Estado brasileño. En esta relación interétnica, además de Txitxopi, los korubo nombraron a otros hombres como caciques para representar a tres de las cuatro aldeas. Una de las aldeas korubo no tenía cacique, ya que era la «aldea de Maya» ("aldeia da Maya”), una matxo. Actualmente, Maya constituye la principal referencia de autoridad entre los korubo en el río Ituí.

Todo indicaba que el término «cacique», introducido entre los korubo a través del contacto interétnico, se utilizaba, sobre todo, en contextos en los que se trataba con personas no indígenas, mientras que fuera de estos contextos, otros términos de la lengua korubo, como matxo, ganaban espacio. Sugiero, por lo tanto, un acercamiento inicial a algunas transformaciones en las relaciones de género y formas de representación colectiva, influenciadas por el contacto permanente de los korubo con las instituciones estatales y indigenistas. Tales transformaciones son tangenciales a la creación de un liderazgo masculino donde existían formas de autoridad femenina.

Este artículo está dividido en cinco secciones. Inicialmente, presentaré un breve panorama del contacto entre el Estado brasileño y los korubo. En la segunda y tercera sección, analizaré el proceso en el que ciertos hombres fueron elegidos por los korubo para ocupar un nuevo cargo introducido en el contacto interétnico: cacique. Finalmente, en la cuarta y quinta sección, abordaré el caso de Maya, en cuanto matxo, y la posición de las mujeres mayores entre los korubo del río Ituí.

Con la pandemia del nuevo coronavirus, la investigación de campo fue interrumpida por la Portaria $n^{\circ} 419 / 2020 / F U N A I$, que restringió el acceso de civiles a tierras indígenas para contener la propagación del virus. Esta investigación doctoral fue apoyada por una beca de investigación del Conselho Nacional de Pesquisa Científica (CNPq, Brasil) y fondos para investigación de campo de Legs Lelong en Anthropologie Sociale, de l'Institut des Sciences Humaines et Sociales du Centre National de la Recherche Scientifique (CNRS, Francia). 


\section{REPENSANDO EL «CONTACTO INICIAL»}

Gran parte de lo que sabíamos sobre los korubo, hasta hace poco, se refiere a contactos con personas no indígenas, registrados en los volúmenes Povos Indígenas no Brasil, del Instituto Socioambiental, y en la biblioteca virtual de MI/ $\mathrm{FUNAI}^{3}$. Estos contactos, aproximaciones y distanciamientos entre los korubo y los no indígenas, precedieron a la relación permanente establecida con el Estado brasileño a través de su órgano indigenista, la FUNAI.

La relación permanente de los korubo con las instituciones estatales y indigenistas tiene cuatro hitos, en los años 1996, 2014, 2015 y 2019; períodos en los que el Estado brasileño contactó a diferentes cronogrupos ${ }^{4}$. Conceptos como «subgrupo» $\mathrm{y}$ «conjunto» tienen una connotación densa en la literatura etnológica sobre los pueblos amerindios de las tierras bajas de América del Sur, como los de las familias lingüísticas katukina, arawá y pano. Por lo tanto, en el caso korubo utilizaré el término «cronogrupo» para referirme a las colectividades contactadas por la FUNAI en diferentes momentos y lugares, dentro de la tierra indígena, cuya temporalidad de contacto interétnico estableció diferentes inserciones de estas en la relación con los no indígenas.

En Brasil, las expediciones de contacto con pueblos amerindios implican el establecimiento de un "campamento de contacto» ("acampamento de contato") por la FUNAI y el monitoreo de la salud de los recientemente contactados por la SESAI. Solo hubo dos expediciones de contacto exitosas con los cronogrupos korubo (en 1996 y 2019), ya que en 2014 y 2015, los cronogrupos fueron contactados primero por otros pueblos indígenas (los kanamari y los matis), luego por la FUNAI, que manejó la logística adecuada para situaciones de contacto5.

Antes del trabajo de la FUNAI con los cronogrupos, se registra una historia de conflictos y muertes que resultaron en la muerte de prácticamente todos los ancianos korubo. En diversos aspectos, la experiencia korubo es similar a la de

Las principales referencias sobre los contactos de la FUNAI con los korubo, accesibles al público, son Amorim (2017), Arisi (2007), Erikson (2000), Matos (2019), Pereira (2018) y Vargas da Silva (2017).

4 Es una propuesta provisional, que se irá madurando con el tiempo. Para este artículo, considero que el término «cronogrupo» servirá a los propósitos de la discusión. Para más detalle se puede consultar la tabla 1, contactos oficiales de la FUNAI con los korubo en la siguiente sección.

5 En este artículo no me ceñiré a los detalles de los contactos de la FUNAI con los cronogrupos, ya que es posible encontrar un resumen de la bibliografía sobre este tema en Histórico do contato (Silva, 2021). 
otros pueblos amazónicos, incluidos los de la familia lingüística pano que habitan en el valle de Yavarí. Es muy conocida la acción de los frentes extractivos en toda la Amazonía. Los períodos de extracción de caucho, madera y prospección de petróleo, a lo largo de los siglos XIX y XX, conforman la historiografía del valle del Yavarí. Las reacciones de los pueblos amazónicos ante la penetración de estos frentes extractivos fueron diversas: desde un enfrentamiento militar hasta una aproximación estratégica y pacífica.

En el caso de los pueblos de habla pano, ese período que precedió a la relación permanente con la FUNAI se caracterizó por dispersiones de malocas y grupos familiares (caso kulina-pano, D’Ávila, 2018; matsés, Matos, 2014; Coutinho Júnior, 2017; matis, Erikson, 1996, 2002). El caso korubo es similar a estos casos en lo que respecta a las divisiones y dispersiones de grupos familiares y el establecimiento de acercamientos y distancias con otros pueblos, incluso los no indígenas, en el contexto de la explotación extractiva. Sin embargo, la belicosidad característica de los pano septentrionales se acentuó al extremo, sobre todo porque los korubo ocupaban el curso inferior de los ríos y, por lo tanto, estaban cerca de las comunidades no indígenas.

Tradicionalmente, la porción septentrional del «macroconjunto pano» (Erikson, 1993) se relacionaba a través de guerras endémicas, acusaciones de brujería, venganzas y raptos de mujeres y niños, generando procesos de fisión, dispersión social y redefinición de colectivos (Erikson, 1986; 1994; Matos, 2017). En el valle del Yavarí, esta característica se acentuó por el contexto de explotación extractiva, que dio lugar a ataques a malocas y secuestros de mujeres y niños, como el ataque matis a la maloca korubo en 1920 (Erikson, 1996, p. 96; Arisi, 2007, pp. 76-88). La intensificación de estos conflictos promovió divisiones y reorganización de grupos familiares, como el secuestro de dos mujeres korubo antes de la década de 1990, factor que reconfiguró la ocupación korubo en los ríos Ituí y Coari (Vargas da Silva, 2017, pp. 136-137).

Con el incremento de esta belicosidad, los no indígenas se convirtieron en los principales enemigos de los korubo. La colección documental registra numerosos conflictos y muertes que involucran a los korubo, entonces «aislados», y a personas no indígenas que penetraron en el territorio, incluso a empleados de la FUNAI $^{6}$. Los primeros registros de conflictos entre los korubo y los no indígenas

6 Existe un debate sobre estas categorías estatales (contacto reciente, aislados, aislamiento). Aquí destaco solo el sentido en que uso esta categoría: «El término "aislamiento" marca, sobre todo, la ausencia de subordinación directa al aparato administrativo del Estado» (Viveiros de Castro, 2019, p. 12). 
se remontan a principios del siglo XX. En la década de 1960, hubo una intensificación de los conflictos que se prolongaron hasta la década de 1990. A lo largo de este período, los korubo fueron cada vez más acorralados por las actividades extractivas en la región.

Los korubo aparecían en los alojamientos de los extractivistas y robaban objetos industrializados. Mostraban su disgusto por la presencia no indígena rompiendo objetos y colocando obstáculos y barreras ("tapagens") en senderos del bosque. Asediaban los rozaderos de los no indígenas, especialmente en la década de 1990, cuando la constante huida resultante de estos conflictos dificultó el mantenimiento de las chacras y las malocas korubo. Ese registro configuró una narrativa de constante fuga por los korubo, marcada por enfermedades y declives poblacionales, producto de aproximaciones específicas con pueblos no indígenas y otros pueblos. Esta situación de acorralamiento culminó con la primera expedición de contacto exitosa entre la FUNAI y un cronogrupo en 1996.

Desde 1972, la FUNAI trataba de establecer contacto pacífico con los korubo. Estos intentos resultarán en la muerte de varios empleados de la institución indigenista que fueron golpeados con garrotes (“cacetes") por los korubo ${ }^{7}$. Meses después de la exitosa expedición de contacto, que tuvo lugar en 1996, los korubo asesinaron a otro empleado de la FUNAI: Raimundo Magalhães, llamado Sobral. Solo después de la muerte de Sobral es que podemos decir que se inició un proceso de relaciones más o menos estables entre los korubo y el Estado brasileño.

Las aproximaciones esporádicas con los korubo, las enfermedades y muertes entre ellos, fueron factores que los llevaron a aparecer con frecuencia en las chacras o huertos ajenos y en las orillas de los ríos. Años después, esta secuencia cíclica culminó con la intervención del órgano indigenista con otros cronogrupos en 2014 y $2015^{8}$. Esto configuró un proceso múltiple de contactos entre la FUNAI y los diversos cronogrupos. En gran medida, la complejidad de este proceso proviene de la participación de los korubo, quienes establecieron relaciones permanentes con el Estado brasileño en 1996, como traductores y mediadores en los contactos posteriores entre la FUNAI y los demás cronogrupos.

7 Los diferentes tipos de garrotes fabricados y utilizados por los korubo se conocen regionalmente como "cacetes". Sumado a la larga historia de conflictos y muertes, esto ha hecho que los korubo sean conocidos como «los caceteiros del valle del Yavarí» ("os caceteiros do Vale do Javari").

8 La motivación de la expedición de contacto de la FUNAI con el cronogrupo en el río Coari, que tuvo lugar en 2019, difiere de las motivaciones de los contactos realizados en 2014 y 2015 (cf. Silva, 2021). 
A los efectos de este artículo, lo que nos interesa a lo largo de este proceso es observar los múltiples acercamientos y separaciones que los korubo establecieron con otros pueblos y con pueblos no indígenas ante la acción de la FUNAI y las relaciones permanentes con el Estado brasileño. Considerando la belicosidad de los pueblos de lengua pano, el contexto extractivo en la región y las muertes, saqueos y secuestros que involucran a los korubo, una pregunta se vuelve fructífera para la reflexión: ¿en qué medida el éxito de la primera expedición de contacto de la FUNAI con el cronogrupo en 1996 fue también posible por un cambio en su estrategia de relacionamento con los no indígenas?

La bibliografía revela un rechazo inicial de los korubo en establecer relaciones permanentes con los no indígenas. Este rechazo se expresó en continuas fugas y dispersiones, combinadas con momentos de acercamientos puntuales con los no indígenas para saquear rozaderos y obtener herramientas de metal y bienes. En la década de 1990, los korubo fueron arrinconados y el acercamiento se convirtió en una estrategia de protección contra los ataques enemigos. Los korubo, literalmente, se dejaron contactar por el órgano indigenista en 1996. A priori, el éxito de esta expedición no significó el inicio de relaciones pacíficas, como ejemplifica la muerte de Sobral ese mismo año.

Con el cambio de estrategia de este primer cronogrupo en la relación con los no indígenas, se comenzó a escribir una nueva etapa en la historia de los korubo. Las huidas constantes cesaron y se inició un largo y lento proceso de sedentarización de estas personas en las orillas del río Ituí. Gradualmente, los korubo volvieron a construir malocas y abrir chacras. Este proceso se complejizó cuando, al cronogrupo contactado en 1996, se sumaron los otros cronogrupos contactados en 2014 y 2015.

Al llegar al campo en 2019, encontré una configuración de cuatro aldeas korubo en el curso bajo del río Ituí, que reunía a personas de los diferentes cronogrupos contactados por el Estado brasileño en 1996, 2014 y 2015. El cronogrupo, cuya expedición de contacto tuvo lugar en marzo de 2019, permaneció en el río Coari, separado de los otros cronogrupos ubicados en el río Ituí. Este proceso, abreviado en el concepto de «contacto», puede pensarse de dos maneras.

Por un lado, desde el punto de vista del Estado brasileño, los cronogrupos, antes aislados, se han convertido en un «pueblo de contacto reciente» ${ }^{9}$. Por otro

9 Repensar el «contacto inicial» con los korubo requiere una reflexión sobre este cambio categórico operado por la organización indigenista: de la categoría «aislado» al «contacto reciente». Si pensamos que el cronogrupo, cuya expedición de contacto de la FUNAI tuvo lugar en 2019, ya está incluido en la misma categoría (contacto reciente) que los korubo que han mantenido 
lado, desde el punto de vista del mundo vivido por los korubo, personas que no necesariamente se consideraban emparentadas comenzaron a vivir juntas; los distintos grupos familiares que integraban los cronogrupos fueron amalgamados por el Estado bajo el etnónimo korubo; dentro de una misma aldea coexistían diferentes niveles de acceso a los no indígenas, sus conocimientos y sus tecnologías. Este segundo punto de vista iluminará el tema del surgimiento del cargo de «cacique» en la siguiente sección.

En diálogo con la propuesta de este dossier, repensar el contacto inicial con los korubo es partir de una visión procesual. Además de la acción del Estado brasileño a través de las instituciones indigenistas (FUNAI y SESAI), la relación entre los korubo y los no indígenas involucró múltiples acercamientos y distanciamientos y evidenció un cambio de estrategia: de la huida a la sedentarización; desde el uso de garrotes hasta la apropiación de un nuevo cargo para el diálogo interétnico (el cacique). En este cambio de estrategia, la apropiación de la noción de «cacique» por los korubo indica una reconfiguración relacional. Una nueva forma para que los korubo se vinculen con los no indígenas.

\section{CUATRO HOMBRES, CUATRO CACIQUES}

Cuando llegué al campo, en enero de 2019, los korubo ya utilizaban la palabra «cacique» para referirse a un hombre entre ellos, Txitxopi, como mencioné en la introducción. A lo largo de 2019 y 2020, esta palabra llegó a usarse en ciertos contextos para referirse a otros hombres korubo. Además de la palabra «cacique», similar a los no indígenas, los korubo han adoptado la palabra «jefe» para referirse a los cargos que ocupan los no indígenas en instituciones indigenistas, como los jefes de la BAPE/FUNAI y la FPEVJ/FUNAI.

Aunque no estuve presente cuando Txitxopi fue nominado como «cacique», a lo largo de 2019 y 2020 fui testigo de diferentes contextos en los que este cargo fue utilizado por las instituciones y por los korubo. Fui testigo de los reemplazos del cacique general (representante de todas las aldeas korubo) por un jefe suplente. Por lo tanto, los registros documentales, los diálogos con funcionarios

relaciones continuas con el Estado brasileño desde 1996, esta transición entre categorías parece repentina y engendra una serie de complejidades. Acerca de la definición oficial del Estado brasileño para la categoría «contacto reciente», leer: http://www.funai.gov.br/index.php/ nossas-acoes/povos-indigenas-isolados-e-de-recente-contato?start=1\#: :text=A\%20Funai $\% 20$ considera $\% 20 \% 22 \mathrm{de} \% 20$ reciente, nacional\% 20e\% 20 selectividad $\% 20$ (autonomía)\% 20na. Acceso: 03/07/21. 
de organismos estatales y los datos etnográficos dilucidan parte del surgimiento del cargo de cacique entre los korubo en el río Ituí.

Las dos primeras tesis de maestría que tienen como tema principal a los korubo no mencionan la existencia de caciques entre estos (cf. Oliveira, 2009; Vargas da Silva, 2017). Sin embargo, en 2016, un informe elaborado para la FPEVJ/FUNAI mencionó a un cacique. En referencia a las actividades de alfabetización con los korubo, el informe registró que: «Txitxopi, nuevo cacique que no participó del taller, pidió que enviara su nombre, el de sus esposas y de sus hijos por escrito» (Oliveira, 2016, p. 12, cursivas mías). En esa época, se estimaba que Txitxopi tenía treinta años. Se trataba de un cargo en proceso de incorporación por los korubo. ¿Cómo este surgió entre ellos?

Sabemos que, durante las experiencias de contacto entre el Estado brasileño y los pueblos amerindios, surge la necesidad de personas que puedan ser portavoces de la comunidad. Uno de los ejemplos más notables fue el contacto entre la FUNAI y los waimiri-atroari. Sin embargo, esta reunión evidenció un desajuste entre lo que los agentes estatales concibieron como «liderazgo indígena» y el liderazgo tradicional de los hombres mayores (Baines, 1991, p. 285).

El caso korubo, según el apartado anterior, revela un proceso de múltiples contactos entre los cronogrupos y la FUNAI. La multiplicidad de este proceso y, por lo tanto, su complejidad llevó a la institución indigenista a crear estrategias para identificar los diferentes cronogrupos después de los «campamentos de contacto», como la denominación de estos cronogrupos:

Tabla 1. Contactos oficiales de la FUNAI con los korubo

\begin{tabular}{cccc}
\hline Fecha de contacto & $\begin{array}{c}\text { Ubicación de } \\
\text { contacto }\end{array}$ & $\begin{array}{c}\text { Cita otorgada por la } \\
\text { FUNAI }\end{array}$ & $\begin{array}{c}\text { Número de } \\
\text { personas contac- } \\
\text { tadas }\end{array}$ \\
\hline Octubre de 1996 & río Ituí & Grupo da Maya & 18 \\
Septiembre de 2014 & río Itaquaí & $\begin{array}{c}\text { Grupo do Visa } \\
\text { (Grupo do Marubão) }\end{array}$ & 6 \\
Octubre de 2014 & río Itaquaí & $\begin{array}{c}\text { Grupo do Pinu } \\
\text { (Grupo do Marubão) }\end{array}$ & 15 \\
Septiembre de 2015 & río Branco & Grupo do Xuxu & 10 \\
Octubre de 2015 & río Branco & Grupo da Maluxin & 11 \\
Marzo de 2019 & río Coari & Grupo do Makwëx & 34 \\
& & (Grupo do Coari) & \\
\hline
\end{tabular}


Inicialmente, hubo consenso en que la referencia del primer cronogrupo era una mujer: Maya. Por esta razón, la FUNAI nombró al cronogrupo contactado en 1996 como el «grupo de Maya». Tal consenso es explícito en los discursos de los empleados de la FUNAI y en los documentales grabados con este primer cronogrupo. En 2014, la referencia no fue tan evidente como en 1996, y la expedición de contacto se realizó en dos etapas: primero, con el «grupo de Visa»; luego con el «grupo de Pinu». En 2015 sucedió algo similar: primero se contactó al «grupo de Xuxu»y, después, al «grupo de Maluxin» ${ }^{10}$.

Estos distintos cronogrupos fueron reunidos por el Estado brasileño después de conflictos internos, enfermedades y muertes entre los korubo. Esta estrategia de nomenclatura para los diferentes cronogrupos se basó en su asociación con el fenotipo o rasgo conductual de la persona icono, como fue el caso del «grupo de Pinu», por él ser «extrovertido y articulado» y tener una «mancha en la cara» (Vargas da Silva, 2017, p. 87), o incluso haciendo referencia a topónimos, como el «grupo del Marubão» y el «grupo del Coari».

Después de la expedición de contacto con el primer cronogrupo en 1996, Maya parecía a los no indígenas una figura prominente. Retomaré este argumento en la siguiente sección. En ese momento, el cronogrupo no presentaba mayores dificultades para ser identificado por los agentes estatales. Sin embargo, a medida que se establecieron otros contactos con otros cronogrupos en diferentes ríos dentro de la tierra indígena a lo largo de los años, la necesidad de identificarlos y dialogar con ellos se hizo latente.

La ausencia de mención explícita de los jefes tradicionales entre los korubo en los contactos realizados en 2014 y 2015 por la FUNAI y, al mismo tiempo, la necesidad de que el órgano indigenista nombre los diferentes cronogrupos en función de fenotipos o topónimos revela que, para la FUNAI, en ese momento los korubo no contaban con un modelo que pudiese ser reconocido como jefatura tradicional.

El puesto de jefe entre los korubo parece haber surgido tras los contactos de la FUNAI con los cronogrupos en 2014 y 2015. Solo así sería posible que Txitxopi fue referido como el «nuevo cacique» en Oliveira (2016, p. 12). Si los cronogrupos no presentaron jefes tradicionales en contacto con el Estado brasileño en 2014 y 2015, y el registro de un «nuevo cacique» entre ellos data de 2016,

10 Los funcionarios de la FUNAI se refirieron al cronogrupo, contactado en marzo de 2019 en el río Coari, como el «grupo de Makwëx». Makwëx es uno de los hombres más viejos de este cronogrupo. Solo la investigación de campo futura entre este cronogrupo en el río Coari aclarará si Makwëx es, de hecho, un jefe tradicional. 
podríamos preguntarnos: ¿cómo, entre 2016 y 2019, la figura del cacique, todavía en surgimiento, se multiplicó entre los korubo del río Ituí?

En 2016, tenían un cacique. Tres años después, tenían cuatro. Una posible respuesta a esta pregunta está en la construcción de nuevas aldeas korubo a orillas del río Ituí. Esta configuración de aldeas a orillas del río es tan reciente como el surgimiento del cargo de cacique entre los korubo. El contingente poblacional y el número de aldeas ha experimentado cambios en los últimos años.

Luego de la expedición de contacto realizada por la FUNAI en 1996, el grupo de Maya permaneció en igarapé Quebrado, en el margen izquierdo del río Ituí, cerca de la BAPE/FUNAI, ubicada en la confluencia de los ríos Ituí y Itaquaí. En esa localidad, este cronogrupo estableció la aldea Roça. En 2007, los korubo poseían dos aldeas en el río Ituí: además de la aldea Roça, fundaron Tapalaya.

Luego de los contactos de la FUNAI con los cronogrupos en 2014 y 2015, surgió la necesidad de abrir campos de cultivo para formar nuevas aldeas cercanas a Tapalaya y albergar a los recién contactados. Así, entre 2017 y 2019, hubo un crecimiento poblacional como producto de los contactos realizados en 2014 y 2015. Fue necesario construir nuevas aldeas para que los cronogrupos recién contactados pudieran sumarse al grupo de la Maya en el río Ituí.

En 2019, los korubo poseían cuatro aldeas en el curso inferior del río Ituí: una ubicada en el margen derecho (Vuku Maë) y las otras tres ubicadas en el margen izquierdo (Tankala Maë, Tapalaya y Sentele Maë). Durante el trabajo de campo, observé cambios en la estructura física, como la construcción de viviendas unifamiliares alrededor de las malocas, y en el contingente poblacional de estas aldeas.

Con el encuentro de los cronogrupos a orillas del río Ituí, la convivencia entre los korubo desencadenó relaciones de proximidad, pero también conflictos entre distintas familias. Los conflictos internos se produjeron principalmente por las relaciones extramatrimoniales y constituyeron uno de los principales factores para la apertura de nuevas aldeas. Después de los conflictos familiares, era común que las familias se trasladaran de aldea en aldea o establecieran una residencia temporal en una aldea vecina.

La sedentarización a orillas de los ríos, la consolidación de una identificación con el etnónimo «korubo», las relaciones amistosas y cercanas entre grupos familiares aún no se consolidaban. La apertura de nuevas aldeas para albergar a los cronogrupos recién contactados promovió la replicación del cargo de cacique. Cada aldea korubo necesitaba un portavoz para hablar con las instituciones indigenistas (FUNAI y SESAI). 
En 2019 y 2020, con la excepción de Vuku Maë (traducida por los korubo como «aldea de Maya»), cada una de las tres aldeas tenía un hombre en el cargo de cacique $^{11}$. Sin embargo, la mayor de ellas, Tankala Maë, tenía dos hombres en ese puesto: el cacique general y el sustituto. Sentele Maë tenía a Malevo como cacique; Tapalaya tenía a Takvan como cacique; Tankala Maë tenía a Txitxopi como su cacique, quien también era el cacique general, con Lëyu como su sustituto.

Había cierto consenso entre los korubo acerca de que estos hombres fueran nombrados como caciques para la comunicación interétnica. En ausencia de Txitxopi, los korubo les indicaban a los no indígenas que Lëyu pasaría a ser el cacique. Estos hombres se ausentaban de las aldeas por dos motivos principales: (i) los traslados sanitarios de la SESAI a los hospitales y las Casas de Saúde do Índio (CASAI/SESAI) en las ciudades, y (ii) el retiro de documentos o recibo de pagos por trabajos remunerados prestados a FUNAI. Todos los caciques se ausentaban de las aldeas por estas razones, pero solo el cacique general tenía un reemplazo.

Las actividades remuneradas de la FUNAI consistieron en mediar, traducir y cazar durante la vigilancia etnoambiental en la BAPE/FUNAI Ituí-Itaquaí y en el acampamento de contacto con el cronogrupo contactado en 2019 en el río Coari. En estas actividades, los hombres del grupo de Maya eran reclutados por la FUNAI. Los cuatro hombres elegidos para asumir el cargo de cacique nacieron antes de la expedición de contacto realizada por la FUNAI en 1996. Así, las familias del grupo de Maya se distinguian del resto de familias korubo. Esta diferencia, resaltada por los propios korubo, evidenciaba el «tiempo de contacto» con los no indígenas.

El grupo de Maya poseía un acceso diferenciado a la lengua portuguesa y un conocimiento del mundo no indígena diferente al de los otros korubo y, hasta cierto punto, influenciaba en las relaciones de los otros korubo con los no indígenas. Inicialmente, los korubo adquirían dinero mediante la venta de artefactos (armas, cestería etc.). Sin embargo, en 2019, su principal fuente de remuneración pasó a ser las actividades de la FUNAI. A partir de entonces, comenzaron a tener acceso a bienes como motores peque-peque, generadores de energía eléctrica, entre otros.

Al reclutar hombres del grupo de Maya, la FUNAI fomentaba la distinción entre grupos familiares. El acceso a documentos de identificación personal, dinero

11 Los korubo no habían incorporado el significado femenino del término cacique (cacica). La forma en que los korubo se referían a Maya se discutirá en la cuarta sección. En este artículo, el término «caciques korubo» se refiere a estos cuatro hombres. 
$\mathrm{y}$, en consecuencia, objetos industrializados, y la circulación en las ciudades eran desiguales entre los korubo del río Ituí. Los hombres del grupo de Maya también participaban en actividades como los proyectos y la compra y venta de artefactos en ferias artesanales ("feiras de artesanato"). Los hombres eran reclutados para estas actividades por poseer documentos de identificación, no tener bebés, y poseer algún nível de conocimiento de la lengua portuguesa. Entonces, el perfil de las personas que accedían a estas actividades eran hombres jóvenes y hombres adultos, como los caciques. La mayoría de las mujeres estaban casadas y tenían bebés o no salían de las aldeas sin sus maridos ${ }^{12}$.

El dominio de la lengua portuguesa entre los cuatro caciques variaba. Entre ellos, Malevo era el que más hablaba portugués. Actuaba como traductor de los demás korubo y tenía cierto nivel de conocimiento de la escritura en el idioma korubo. Malevo conocía otras ciudades, además de Tabatinga, como Manaus y Río de Janeiro ${ }^{13}$. A diferencia de Malevo, Txitxopi entendía algo del idioma portugués, pero hablaba poco. Lëyu y Takvan también entendían algo, pero tenían dificultades para hablar este idioma.

El dominio del idioma portugués, aunque facilitaba la inserción de hombres del grupo de Maya a actividades específicas, no era uno de los criterios para convertirse en un cacique korubo. En este sentido, la posición de cacique entre los korubo difiere de otros contextos, en los que la alfabetización, el bilingüismo y el acceso a otros conocimientos no indígenas son triunfos desencadenados por figuras importantes (cf. Chaumeil, 1990; Brown, 1993; Ramos, 1998; Oakdale, 2004; Virtanen, 2009; Calavia Saéz, 2010). Sin embargo, había una disparidad creciente entre la familia de los caciques y las demás familias. Los caciques y sus familiares, jóvenes muchachos, eran los que más circulaban entre las aldeas, la BAPE Ituí-Itaquaí y las ciudades, ya sea para trabajar con la FUNAI o para las mudanzas sanitarias de la SESAI.

12 Una de las excepciones era Maya. A pesar de esto, ella no era la primera opción de la FUNAI para participar en estas actividades.

13 Esta diferencia de Malevo fue reflejo de su participación en actividades de alfabetización en la BAPE/FUNAI antes de 2007. En esa época, Malevo y Takvan Vakwë eran los dos korubo que participaban en esas actividades. Debido al nivel de conocimientos adquiridos en las actividades de alfabetización, fueron seleccionados como becarios del Prodoclin. Por eso, en 2018 participaron del taller en MI/FUNAI, Río de Janeiro. 


\section{ATRIBUCIONES DE LOS CACIQUES KORUBO}

La literatura sobre los pueblos de la familia lingüística pano y pueblos vecinos en el valle del Yavarí revela aspectos interesantes para la comparación con el surgimiento del cargo de cacique entre los korubo del río Ituí. En esta literatura, existen algunos debates que involucran las funciones de jefe y chamán, y la diferenciación entre jefes tradicionales y figuras surgidas en el contacto interétnico, como caciques, patrones, tuxauas y otras formas de liderazgo indígena concebidas por los no indígenas.

En diferentes contextos, las figuras surgidas en contactos interétnicos tuvieron diferentes rangos de actuación. Se observa un mayor contraste en los casos kulinapano (lengua pano) y kanamari (lengua katukina). Mientras que los kulina-pano tenían dos caciques: un cacique para actuar dentro de las aldeas y otro para mediar con los no indígenas (D'Ávila, 2018, p. 103), la mayoría de las aldeas kanamari, después de la influencia de un funcionario de la FUNAI, tenían varias personas autodenominadas caciques, pero sin poderes efectivos (Costa, 2007, pp. 195-196).

Entre los marubo (de lengua pano), el caso de los «patrones» es interesante, porque se encuentra en el límite entre la jefatura tradicional y las figuras que surgen en el contacto interétnico. Por un lado, los «patrones marubo», poseedores de bienes y objetos industrializados, no podían ser chamanes, ya que las funciones de patrón y chamán eran incompatibles; por el otro, los patrones se parecían a la jefatura tradicional marubo por su capacidad de movilizar al colectivo (Melatti, 1985, pp. 182-186).

En el caso korubo, los hombres designados como caciques no correspondían exactamente a un tipo de jefatura tradicional, ni acumulaban funciones chamánicas. Eran hombres elegidos por los korubo a partir del incentivo de las instituciones estatales y indigenistas para el diálogo interétnico. Estos hombres probablemente fueron elegidos por su parentesco con Maya, como demostraré en la siguiente sección.

En un aspecto, los caciques korubo eran similares a los patrones marubo por su capacidad de concentrar los recursos, bienes y objetos industrializados, característica que los distinguía de los demás korubo. En una misma aldea korubo, estos hombres conseguían dinero para comprar el segundo motor peque-peque, mientras que otros hombres jamás poseían la cantidad monetaria para ese tipo de adquisición.

Sin embargo, en otro aspecto los caciques korubo se diferenciaban de los patrones marubo: su capacidad de movilización colectiva. El cargo que ocupaban 
estos hombres no correspondía con la concepción no indígena y estatal de las atribuciones de un cacique. Para los no indígenas, cada cacique korubo debería ser el «responsable» por su aldea, dentro y fuera de ella. Sin embargo, el rango de acción de estos hombres era limitado.

Los caciques no movilizaban a las aldeas para actividades colectivas, como la apertura de campos de cultivo, ya que no eran jefes tradicionales, ni existía una identificación con la idea de «pueblo» que utiliza la institución indigenista. Esto se evidenciaba cada vez que la FUNAI comunicaba a los korubo que habría actividades colectivas, como ferias de artesanías. En una de estas ocasiones, una de las matxo argumentó algo que expresa la forma como los korubo se percibían a sí mismos: a cada feria artesanal, debían ir solo las personas de una aldea, pues así no habría conflicto entre ellas. Los korubo se organizaban bajo la lógica de diferentes grupos familiares, evidenciado en la composición de las cuatro aldeas del río Ituí.

El caso de los waimiri-atroari, analizado por Baines (1991), es un buen ejemplo para la reflexión. Tanto los capitanes waimiri-atroari como los caciques korubo surgieron ante la necesidad de voceros para la comunicación con el Estado y las instituciones indigenistas. Las políticas y acciones de Estado, a su vez, contribuyeron a la consolidación de estas figuras emergentes, favoreciendo su acceso a determinados recursos.

Sin embargo, la diferenciación entre los grupos familiares korubo, fomentada por el Estado brasileño, no se convertiría en un instrumento de poder de los caciques para aglutinar a los diferentes grupos familiares. Por lo tanto, los caciques korubo hablaban por sus familias con el Estado, pero no necesariamente hablaban por todas las familias korubo. Entonces, podríamos preguntarnos: ¿cuáles eran las funciones que desempeñaban estos cuatro hombres korubo designados como caciques?

La literatura etnográfica sobre pueblos de lengua pano muestra un perfil de liderazgo masculino. Los jefes tradicionales eran hombres, generalmente más viejos, casados y con más de una esposa. En estos casos, la poligamia se presentaba como una condición para el liderazgo tradicional, una ventaja necesaria para los jefes, porque cuantas más esposas tuvieran, mayor sería la capacidad de concentrar y distribuir recursos y de recibir visitas (cf. caso yawanawá, Carid Naveira, 1999, p. 78; kaxinawá, McCallum, 2003, p. 113).

Las personas nominadas para el cargo de cacique entre los korubo eran hombres casados y con dos esposas. Sin embargo, considerando que los caciques korubo no eran jefes tradicionales, no es de extrañar que la poligamia no 
fuera una característica exclusiva de estos, ya que otros hombres korubo tenían dos esposas. En marzo de 2020, había diecinueve uniones matrimoniales en las aldeas korubo del río Ituí. De estas diecinueve, siete eran matrimonios polígamos. De estos siete, cuatro eran matrimonios de hombres nombrados como caciques.

El perfil de los caciques korubo difiere de la literatura etnográfica en términos de edad. Los cuatro jefes no eran los hombres más viejos ni los más jóvenes entre los korubo. Eran hombres en la edad adulta. De los cuatro, el cacique general era el más joven. Las edades estimadas de los caciques oscilaban entre 34 y 44 años. Al igual que otros hombres, los caciques korubo eran adultos productores en la vida cotidiana de las aldeas: limpiaban huertos, cazaban, pescaban, buscaban leña, recolectaban frutas, etc. Sin embargo, a diferencia de otros hombres korubo, los caciques tenían un mayor acceso y dominio de las tecnologías de caza y pesca no indígenas. Por lo tanto, utilizaban las armas tradicionales (cerbatana, arcoflecha, lanza y garrotes), pero también tecnologías no autóctonas, como motores peque-peque, escopetas, redes, anzuelos y sedal ${ }^{14}$.

Otro aspecto que se destaca en la literatura etnológica son las funciones de un jefe tradicional. Tales funciones consistían en la capacidad de promover la acción colectiva, construir comunidad y malocas, reunir a personas y subgrupos; en distribuir recursos y curar a la gente o incluso cuestionar las instituciones indigenistas (cf. caso kaxinawá, McCallum, 2003, p. 109; kanamari, Costa, 2007, p. 184; marubo, Welper 2009, p. 14; yawanawá, Carid Naveira, 1999, p. 78; matsés, Matos, 2014, p. 141).

En el caso korubo, la función principal de estos hombres como caciques era conversar con los no indígenas. En este sentido, se parecían a los caciques matsés (chuiquid: «el que habla»), aunque no eran «dueños de malocas» (Matos, 2014, p. 141). Un cacique korubo ocupaba el puesto de quien conversa, participa en conversaciones y, sobre todo, invita a conversar, traducido por los korubo como "fazer reunião" (onkeno; onke: conversar, -no: posp.) $)^{15}$. Se trata de una agencia para construir la conversación, expresada en «hacer», en llamar «para

14 El dominio de estas tecnologías no indígenas fue mayor entre los caciques y los hombres jóvenes. Los hombres mayores korubo tenían un mayor control sobre las armas tradicionales.

15 En las lenguas pano de la rama septentrional, los morfemas -no y -ano son posposiciones y adquieren dos significados. El morfema -ano se puede agregar a la cópula (ser/estar), convirtiéndose en una posposición locativa (Fleck, 2013), por ejemplo: Manaus ano (en Manaus). El morfema -no, a su vez, es una posposición sin interpretación locativa, como kutkano (para comer, en lengua korubo) y onkeno (para conversar) (Sanderson Oliveira, comunicación personal). 
conversar», es decir, el cacique korubo tiene la función de convocar a los no indígenas a dialogar.

Los hombres mayores korubo criticaban la postura corporal de algunos jóvenes y recordaban cómo sus antepasados sabían hablar, sosteniendo sus garrotes y con una postura corporal erguida. Si bien los jefes no utilizaban garrotes durante las reuniones con personas no indígenas, la función de estos hombres era discutir un tema determinado para lograr la concreción de las solicitudes korubo. En este sentido, hablar también era reclamar, hablar con personas no indígenas sobre un tema determinado. Por eso, un cacique debería saber hablar y, en este sentido, saber hablar no significaba hablar portugués. Para los korubo, saber hablar estaba relacionado con una postura corporal y una forma de posicionarse frente a los demás. Ese modo tradicional de invitar a conversar y de posicionarse en comunicación con otro parece haber sido asociado, por los korubo, con el cargo surgido en el contacto interétnico: cacique.

En general, las demandas de los caciques korubo giraban en torno a la ejecución de políticas públicas (educación y salud) y la realización de donaciones e intercambios previstas en el Regime de Circulação de Bens (RCB/FUNAI). El $\mathrm{RCB} / \mathrm{FUNAI}$ era un documento que tenía como objetivo «estandarizar» las relaciones de intercambio y venta que se establecían entre los korubo, la FUNAI y otros profesionales que trabajaban con ellos. Para esto, el RCB/FUNAI estipulaba padrones de circulación para los artefactos korubo y artículos manufacturados entre los korubo ${ }^{16}$.

En los diálogos interétnicos, como el encuentro mencionado en la introducción, el cacique general era presentado como «nuestro cacique» ("nosso cacique") por su cuñado o hermano menor, quienes ocupaban el papel de traductores korubo en la comunicación interétnica. La primera pregunta del cacique, traducida por estos jóvenes, solía ser: «¿Cómo piensas trabajar en mi aldea?» (“Como tu pensa trabalhar na minha aldeia?"). Con la mirada fija y entrelazando los dedos de las manos, el cacique cedía la palabra a los no indígenas y esperaba la propuesta. Cada fragmento de conversación era traducido a los dos idiomas: portugués y korubo. Solo después de la escucha inicial, el cacique presentaba el punto de

16 Los artículos donados por la FUNAI a los korubo eran pilas, jabón, encendedores, linternas, limas, machetes y hachas. Los artículos intercambiados, a su vez, eran gasolina, óleo T4 y grasa por mandioca, plátano, pijuayo, harina y otros productos de los huertos korubo. El RCB/FUNAI estipulaba la cantidad, frecuencia y distribución de estos artículos. Con acceso a trabajo remunerado por la FUNAI, los korubo comenzaron a comprar estos artículos, que antes solo se obtenían a través del RCB/FUNAI. 
vista korubo sobre determinado tema: cómo se debería brindar atención médica, cómo se deberían realizar las actividades de alfabetización, etc. Esa era la postura utilizada por el cacique general en conversaciones con personas no indígenas, agentes institucionales y investigadores.

En otras ocasiones informales o momentos de mayor tensión con agentes estatales, a veces se abandonaba la solemnidad y la postura del cacique podía tornarse combativa y contundente, como las denuncias de que a esos funcionarios «se les paga para trabajar con los korubo» ("são pagos para trabalhar com os korubo"), o incluso amenazas de hablar con un «jefe», que ocupase un puesto superior al de la persona en cuestión.

En la medida en que los korubo eligieron a estos cuatro hombres para hablar con los no indígenas, las instituciones estatales, los funcionarios de la FUNAI y los profesionales de la SESAI los interpelaron como portavoces de las colectividades, los «responsables» por sus aldeas. Estos hombres, designados como caciques, eran buscados por el Estado para presentar quejas, recomendaciones y solicitudes, mediar conflictos o intentar establecer acuerdos.

El Estado necesitaba portavoces, y en el contacto interétnico, el cargo de cacique fue incorporado entre los korubo. Nótese que los hombres elegidos por los korubo para ocupar este nuevo cargo portan algunas características de la jefatura tradicional amazónica. Se trata de perfiles de hombres korubo ideales, poseedores de cierta capacidad discursiva a través de la cual pueden advertir a otros. Al mismo tiempo, estas características se sumaron al acceso facilitado por el Estado a figuras emergentes en el contacto interétnico. El Estado, a través de las instituciones indigenistas, contribuía al protagonismo de estos hombres elegidos para ser los caciques, construyendo un diferencial entre estos y los demás hombres korubo.

Es posible que, en el futuro, esta posición se consolide entre los korubo, similar a la concepción no indígena de que un cacique es aquel «responsable» por su aldea, el representante de un «pueblo». Sin embargo, hasta marzo de 2020, el cargo de cacique entre los korubo aún no estaba consolidado. Conforme veremos, la vida cotidiana de las aldeas korubo revelaba un desajuste entre la concepción no indígena de «cacique» y las formas de organización y autoridad vigentes entre los korubo del río Ituí. 


\section{MAYA Y LAS MATXO}

De las nominaciones atribuidas por la FUNAI a los cronogrupos para su identificación luego de los contactos, la única que coincidía con una referencia primaria o actual para los korubo era la de Maya. Para referirse a ella se utilizaron términos como «jefa», «líder», «matriarca» o incluso la expresión «la reina de los korubo» (Arisi, 2007, p. 21; Rodrigo Octavio, 2015, p. 183; Solis et al., 2013). A menudo, quienes escuchan sobre los korubo por la primera vez, escuchan sobre esta mujer que tiene, aproximadamente, sesenta años: «Los korubo contactados en 1996 aparentemente eran liderados por la mujer más vieja entre todos los miembros, llamada Maya, una verdadera matriarca, de formas extrovertidas y discurso firme» (Vargas da Silva, 2017, p. 76, cursiva mía).

La prominencia de Maya entre los korubo estaba relacionada como la causa o la consecuencia de su papel en el contacto con los no indígenas. No es posible afirmar que tuviera un cargo de liderazgo entre los korubo antes de las relaciones permanentes con el Estado brasileño. Sin embargo, según excoordinadores de la FPEVJ/FUNAI, en el pasado, uno de los jefes korubo era un hombre vinculado con Maya. Tras la muerte de este supuesto liderazgo masculino y con la división y dispersión como producto de los conflictos internos y externos con los korubo, «ellos no hablaban de jefes, pero Maya siempre se posicionaba como la líder. Ella decía que ella y Xikxu, su entonces esposo, eran los jefes. Después del contacto con otros indios es que los korubo tenían "cacique"» (FPEVJ/FUNAI, comunicación personal).

Para la FUNAI, Maya ocupó el cargo de un jefe korubo que había muerto antes de empezar a mantener relaciones permanentes con los no indígenas. En este nuevo escenario, ella adquiere un rol protagónico que la ha colocado en una posición de liderazgo entre los korubo. Los mismos korubo enfatizaban el protagonismo de Maya en el establecimiento de relaciones con personas no indígenas, inicialmente, en busca de herramientas de metal:

Xikxu: [...] El río pasaba lejos de donde estábamos. Era en el río Itaquaí. La gente no veía blanco. La gente vivía lejos. Un día Maya fue a la orilla del río y vio mucho blanco. Maya pensó: «No hay cuchillo, no hay olla, no hay dónde poner agua... Voy a buscar la olla de los blancos». Empezó a pedirle a un bote en medio del río.

Maya: Fui a buscar el cuchillo. Cuando fui, los blancos mataron a mi hermano mayor. También mataron a Kanikit Vakwë, Patxi y Paxtu. Luego corrimos de regreso al pueblo [...] (Solis et al., 2013). 
Maya aprovechó este protagonismo para reclamar accesos posibilitados por la FUNAI, como la participación en ferias artesanales y proyectos. Ella hacía hincapié en que no fueron los hombres korubo quienes se pusieron en contacto con los no indígenas. En una de esas ocasiones, en 2019, Maya argumentó que debería participar en actividades y proyectos que involucrasen viajes a diferentes ciudades, ya que fue ella quien hizo contacto con los nawa y protegió el río Ituí, no Xikxu, su exmarido, ni Takvan, su hijo mayor.

La iniciativa de Maya de ponerse en contacto con los no indígenas culminó en conflictos y muertes con no indígenas y entre los korubo. Las muertes provocadas por reacciones violentas de los no indígenas a los intentos de acercarse de los korubo generaron descensos poblacionales y divisiones entre los grupos familiares. Una de estas escisiones ocurrió a fines de la década de 1980 y configuró lo que, en 1996, la FUNAI llamaría el «grupo de Maya». En esa ocasión, ocurrida en 1989, tres hombres korubo fueron asesinados por no indígenas en el lago Gamboá, cerca de la desembocadura del río Itaquaí. Esas tres muertes, resultado de los intentos de aproximación de los korubo a personas no indígenas, crearon tensiones entre Maya y uno de sus hermanos, Nëmulo. Maya, acusada por Nëmulo de ser la principal responsable de las muertes por los contactos con personas no indígenas, tenía tres parientes asesinados por él. Hubo entonces una ruptura entre Maya y Nëmulo, generando una subdivisión entre los korubo después de esas muertes (ISA, 1987/90, p. 278; Vargas da Silva, 2017, pp. 137-139).

El caso es que la posición prominente de Maya entre los korubo del río Ituí estaba relacionada con su papel protagónico en el contacto con los no indígenas. En este sentido, ella se diferenciaba de las demás mujeres korubo. Al mismo tiempo, existían algunas similitudes entre ella y los caciques. Como la mayoría de los caciques, Maya tampoco hablaba portugués y necesitaba la traducción de jóvenes korubo ${ }^{17}$. Aunque Maya no fue la primera opción reclutada por la FUNAI para participar en las actividades, ella tenía documentos de identificación personal y acceso a dinero. En 2019, ella era la única mujer korubo que recibía el beneficio de pensión por vejez del Instituto Nacional do Seguro Social - INSS ${ }^{18}$. Desde

17 Una de las principales traductoras de los diálogos entre Maya y los no indígenas era su hija menor. Entre los korubo del río Ituí, había mujeres jóvenes con un conocimiento razonable del idioma portugués. Sin embargo, la mayoría de ellas estaban casadas y tenían hijos e hijas pequeños. Debido a que eran madres de bebés o porque no podían salir de las aldeas sin sus maridos, estas jóvenes no eran reclutadas para participar en determinadas actividades que les brindasen acceso a viajes, dinero y bienes industrializados.

18 Además de Maya, solo una niña (nieta de Maya) recibía el beneficio del INSS por tener necesidades especiales y vivir bajo el cuidado de SESAI en la CASAI/SESAI en la ciudad de Manaus, Amazonas. 
entonces, otras mujeres korubo han solicitado a la FUNAI acceso a beneficios, como asistencia por maternidad. Sin embargo, hasta 2020, ellas no habían accedido a dicha fuente de ingresos.

Maya se diferenciaba de otras mujeres korubo por haber protagonizado el contacto con no indígenas y por acceder a determinados recursos y conocimientos del mundo no indígena a los que otras mujeres no tenían acceso. Al mismo tiempo, los hombres elegidos para el cargo de cacique se diferenciaban de Maya por ser reclutados, con frecuencia, para trabajos remunerados con la FUNAI y otras actividades, como las ferias y los proyectos. Después del contacto interétnico, Maya y los caciques se diferenciaban de los demás korubo.

Sin embargo, en la medida en que los caciques no poseían autoridad para movilizar a los korubo en actividades colectivas, dentro y fuera de las aldeas, Maya tenía cierto poder sobre los diversos grupos familiares del río Ituí, incluso sobre tareas mayoritariamente masculinas, como la caza. En julio de 2019, uno de los hombres de Vuku Maë, la aldea donde residía Maya, escuchó el sonido de pecaríes cerca de la aldea. Entonces, tomó una canoa y fue a Tankala Maë para convocar a los cazadores. Estos, a su vez, emocionados por la noticia, incluso tomaron sus armas para ir en busca de los pecaríes. Planearon convocar a la aldea de Tapalaya por radio para unirse a la cacería. Sería la población de tres aldeas korubo detrás de los pecaríes: mientras más hombres, más armas y más caza obtendrían.

Sin embargo, Maya, que estaba de visita en Tankala Maë, detuvo inmediatamente la caza. Ella argumentó que solo su yerno - el esposo de su hija menor - podía cazar cerca de su aldea, Vuku Maë. A regañadientes, ya que no había carne en la aldea, los cazadores se sentaron y dejaron, temporalmente, sus planes de lado. Fue necesaria una larga conversación para que Maya cambiase de opinión y la caza de pecaríes fuese autorizada. Maya poseía influencia y autoridad en la vida diaria de las aldeas korubo, no solo entre las mujeres, sino también entre los hombres. Veamos entonces los vínculos de parentesco entre ella y los hombres designados para ocupar el cargo de cacique.

Como se muestra en el diagrama 1, Maya es la madre (tita) de Takvan, Waxmën, Txitxopi y Omon ${ }^{19}$, lo que la convertía, al mismo tiempo, en hermana de la madre (tita utsi: otra madre) y suegra (natxi) de Lëyu y Malevo, casados con Waxmën y Omon. Entre los korubo, el vínculo con la suegra es estricto y se

19 En este artículo, los diagramas 1 y 2 no muestran todos los vínculos de parentesco de ego, solo las relaciones especificadas en las leyendas. 
caracteriza por relaciones de respeto. Excepto en contextos rituales, no se debe bromear con la natxi. Esto caracterizaba las relaciones de autoridad y respeto entre los caciques y Maya. Maya era la que tenía más hijos y yernos entre los korubo del río Ituí. Hablar de «familia de caciques» era también hablar de la familia de Maya, es decir, todo acceso que brindaban las instituciones estatales favorecía al grupo de Maya. Al mismo tiempo, Maya poseía influencia y autoridad sobre los caciques, e influía directa e indirectamente en los diálogos interétnicos.

$\mathrm{Si}$, para los jefes, Maya era madre y suegra, para los korubo ella no era usualmente llamada «jefa», «cacique» o «matriarca». El término utilizado por los korubo para referirse a Maya era matxo. En el idioma korubo, este término se refiere a las mujeres mayores. En el río Ituí, había un grupo de mujeres korubo a las que se hacía referencia con este término. Matxo también era utilizado por los korubo para enfatizar la distinción entre homónimas de diferentes generaciones. En general, las personas distinguían a una niña (txampi) o una mujer adulta (matses) de su homónima, una mujer mayor (matxo) ${ }^{20}$.

El término matxo era utilizado para situar a una mujer en una categoría de mujeres korubo. Las mujeres que, en el transcurso de un proceso, alcanzaban esta posición, pasaban a ser llamadas por el término de parentesco, o nombre propio, más el término matxo, como «Maya matxo», «tita matxo» y «txitxi matxo». Los términos de parentesco para madre (tita) y abuela materna (txitxi) se agregaban a la posición de matxo. Para 2020, además de Maya, había al menos cinco mujeres reconocidas por los korubo como matxo: Waxmën, Luni, Maluxin, Lalanvet y Muna.

Maya tenía entonces lazos de parentesco con los caciques y las matxo. Tres de los cuatro caciques korubo estaban casados con matxo. El único cacique que no estaba casado con una matxo era Malevo. Sin embargo, su primera esposa (Omon), a pesar de no ser una matxo, tenía una influencia central en Sentele Maë, posiblemente por ser una de las hijas de Maya. Algunos funcionarios de la FUNAI decían que todas las hijas de Maya tenían una «postura de liderazgo»; sin embargo, en la vida cotidiana, estos dialogaban, preferentemente, con jóvenes korubo de habla portuguesa y hombres designados como caciques.

20 Por ejemplo, Wio y Wio matxo, cuando los demás se refieren a ellas. En el trato entre ellas, se utilizarían los términos wanxëni (homónima mayor) y wantxuka (homónima menor). 
Diagrama 1. Maya y los caciques

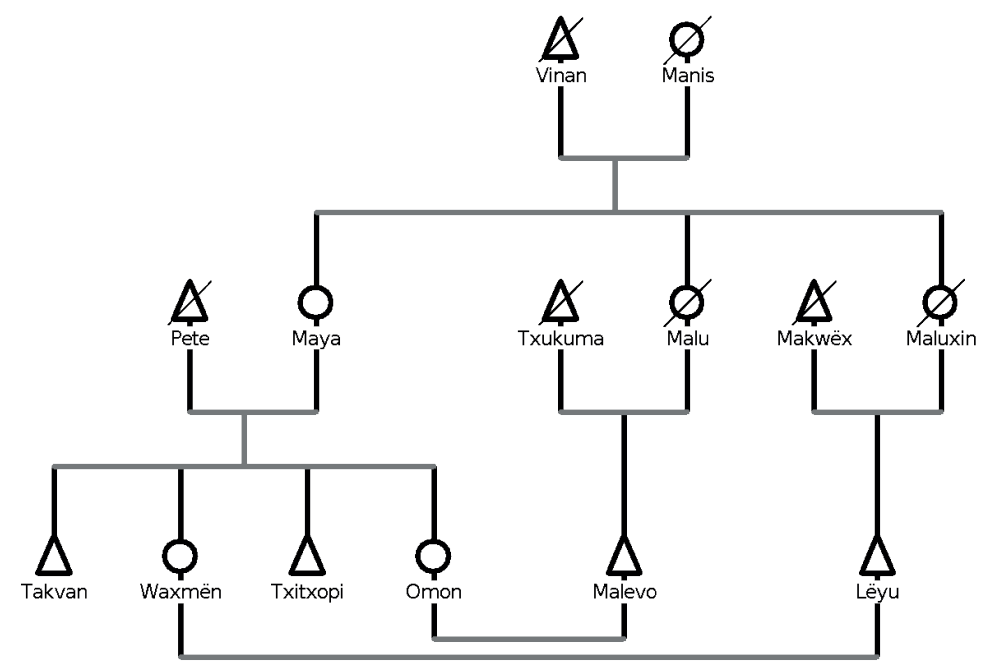

Diagrama 2. Las matxo y los caciques

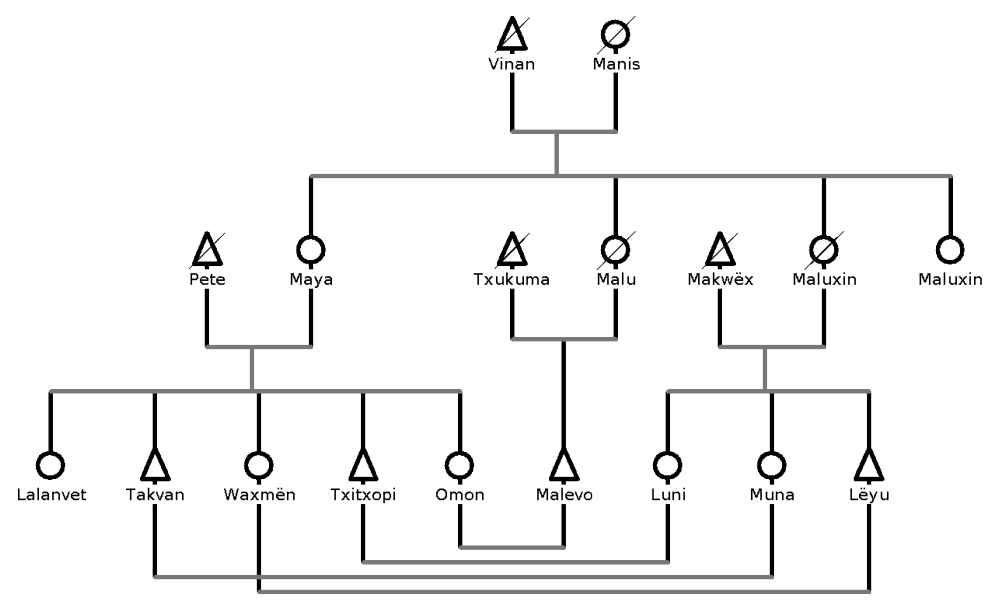


Las matxo no eran llamadas «mujeres líderes», como en el caso kaxinawá (McCallum, 2003, p. 111), a pesar de ser las esposas de los caciques korubo. Sin embargo, ellas poseían autoridad y influencia en la socialidad korubo similar a las «mujeres líderes», casadas con líderes hombres kaxinawá. Esta autoridad se manifestaba en las tareas diarias y reuniones entre los korubo. En las aldeas, las matxo podían dirigir una reunión, incluso si los jefes estaban presentes. La edad estimada de estas mujeres oscilaba entre 38 y 60 años. Entre ellas, solamente una no tuvo nietos ni nietas. Dos de ellas tenían hijos pequeños, respectivamente, de tres y un año de edad. Entre ellas, Maya era la matxo por excelencia por ser la más anciana de todas las mujeres korubo $\mathrm{y}$, al mismo tiempo, aquella que hizo contacto con los no indígenas.

\section{ATRIBUTOS DE LAS MATXO}

El protagonismo en el acercamiento a personas no indígenas, que culminó en la expedición de contacto de la FUNAI de 1996, se sumó a la posición de matxo, creando una diferencia entre Maya y las demás matxo y mujeres korubo. Maya se diferenciaba de las matxo, y estas, a su vez, se distinguían de las mujeres más jóvenes (matses).

Por un lado, la distinción entre las matxo y las matses provenía de su destreza en la ejecución de todas las tareas femeninas. En la relación entre matxo y matses, las matxo ocupaban la posición de maestra-especialista en la producción de todos los artefactos y concentraban determinados conocimientos de producción de artefactos que las matses no poseían, como el saber-hacer la cerámica y los $\operatorname{cestos}^{21}$. Por otro lado, la distinción y antigüedad de las matxo se expresaba en la no ejecución de tareas femeninas, como cocinar, y, al mismo tiempo, en la ejecución de algunas tareas que serían consideradas masculinas, como recoger leña y buscar agua.

Aunque las matxo podían cocinar, por lo general otras mujeres (especialmente, las segundas esposas) o los hombres jóvenes cocinaban para ellos. A diferencia de las matses, las matxo tomaban la liana tatxik (Paullinia sp.), acompañadas, o

21 La disminución de la población entre los korubo, ocurrida antes de los contactos oficiales con la FUNAI, resultó en la concentración de determinados conocimientos entre algunas matxo. Aunque no todas las matxo producían cerámica, las mujeres que producían estos artefactos eran matxo. 
no, por los hombres ${ }^{22}$. La bebida tatxik era ingerida por los cazadores (hombres adultos y jóvenes) y por las matxo. Personas de ambos sexos podían tomar la liana, ya sea solas, o en grupos. Los hombres solían tomarla sentados en bancos individuales, colocados en círculos, en el centro de la maloca, o incluso, en el lado izquierdo de las casas unifamiliares. Las matxo generalmente tomaban sentadas en sus hamacas, a los lados de la maloca o de las casas unifamiliares.

La primera toma de la liana tenía lugar alrededor de las tres o cuatro de la mañana, hora en que los korubo se despertaban, y se repetía a lo largo del día. La bebida era consumida antes y después de la caza, y en los círculos de conversación $^{23}$. Muchas veces, los hombres preparaban la bebida y servían a las matxo, sin embargo, ellas mismas podían prepararla. La misma forma de preparar y beber la bebida era utilizada por ambos géneros: antes de ser rallada, la corteza de la liana se raspaba con un cuchillo; las virutas de liana se humedecían con agua y se exprimían en un recipiente; se retiraba el jugo, exprimiéndolo; el líquido era bebido. Quien preparaba la bebida solía servirla a los demás y beberla en seguida.

Los niños y las mujeres jóvenes no tomaban tatxik. Esta liana también estaba prohibida para las matxo durante la menstruación ${ }^{24}$. Esta prohibición puede ser entendida a partir de la sapidología de los pano (Erikson, 1996; 1999, pp. 251-269) y la hematología amazónica (Belaunde 2006; 2019). Los korubo argumentan que, si tomaban tatxik, las matses quedarían con el cuerpo muy amargo (tximu rapa; tximu: amargo, rapa: int.), y eso no era bueno (vëyla pimen; vëyla: bueno, pimen: neg.). En cambio, las matxo tomaban la liana en cantidades controladas y esto le hacía bien al cuerpo, según decían.

Los korubo también enfatizaban que era en el cuerpo de los hombres donde el tatxik manifestaba su función principal: la potencia cazadora. Si no tomaban el tatxik, los hombres no podrían cazar. Ellos traducían esta incapacidad como "ficar panema": tener mala suerte en la caza. El tatxik, en cuanto sustancia amarga

22 El término tatxik se refiere a la liana y la bebida que se elabora con ella. Esta especie era utilizada por otros pueblos, como los matis del valle del Yavarí y los airo-pai del Putumayo peruano (Erikson, 1996; Bolívar et al., 2004).

23 El tatxik era utilizado en rituales y chamanismo. Aquí me ceñiré a la ingestión de esta bebida por las matxo como práctica que las diferencia de las matses.

24 Entre los korubo, para la menstruación y la reclusión menstrual se utiliza el término tsat vule (tsat: sentar, vule: descer), es decir, permanecer sentada durante el sangrado. Se activaba una red de cuidados alrededor de la reclusa para suplir sus necesidades alimentarias, de modo que no tuviese que circular por la aldea. Entre las matsés, de manera similar al caso korubo, la menstruación ( $t$ sadquid) también se refería al acto de permanecer sentada durante la reclusión (Matos, 2014, p. 76). 
(tximu), se opone a otras sustancias, consideradas dulces (vata), como algunas frutas. Por tanto, el rallador utilizado para preparar la bebida tatxik era de uso exclusivo, es decir, no podía utilizarse para rallar sustancias dulces, y viceversa.

En toda la Amazonía, las sustancias dulces y saladas están contrapuestas al curare, sustancia amarga por excelencia. Lo amargo carga la potencia cazadora y el poder de matar (Erikson, 1996, p. 205). Estas sustancias son fundamentales para la fabricación del cuerpo, ya que los cuerpos fuertes y ideales son hechos, continuamente, a partir del uso de determinadas sustancias, en el caso de los pueblos pano, la regulación de sustancias dulces y amargas que confieren al cuerpo determinadas cualidades sociales y éticas. Entre los korubo, el tatxik era utilizado para este fin. Entre otros pueblos de habla pano, se utilizaban otras sustancias, como la ortiga, el veneno de sapo y la aplicación de hormigas, como en los casos marubo (Melatti, 1992) y matsés (Matos, 2014, p. 87).

La potencia de lo amargo puede verse afectada no solo por sustancias dulces, sino también por la potencia de la sangre. En toda la Amazonía, la sangre de hombres y mujeres alberga una potencia peligrosa que debe ser administrada y controlada por medio de dietas y reclusión. La sangre puede ser un intercambio de piel que produce fertilidad y renovación y, al mismo tiempo, a través del olfato puede producir un efecto de visibilización en las personas ante el ataque de seres extrasociales, una difuminación de las fronteras entre planos (Belaunde, 2006, p. 210).

Por lo tanto, no es sorprendente que la regulación de estas dos sustancias, el tatxik amargo y la sangre menstrual de las mujeres, fuese el objetivo de la atención de los korubo. Por eso, las mujeres que menstruaban no tomaban la liana, ni siquiera las matxo. Las matxo adecuaban su ciclo reproductivo a la ingestión de la sustancia amarga, es decir, ellas no tomaban la liana cuando estaban menstruando. Después de todo, como decían, el tatxik era bueno para los cuerpos de los cazadores y, hasta cierto punto, para los cuerpos de las matxo.

Las matxo eran mujeres mayores que, fértiles o no, ocupaban una posición de preeminencia por su edad. El trato difería de aquel destinado a las matses. Las matxo eran una categoría de entre las mujeres korubo. Entre los matis, Erikson (1999, p. 120) definió a las matxo como mujeres en la menopausia. Según esta definición, las matxo eran mujeres que poseían un «estatus cuasi masculino». Por tanto, podían cometer «trasgresiones legítimas», como comer alimentos prohibidos para mujeres no menopáusicas; sentarse en el centro de la maloca, un espacio reservado para los hombres matis; recibir golpes para la inyección de sho, fuerza oculta y amarga, fuente de poder. 
Entre los korubo, la interrupción de la sangre menstrual no era lo que las definía como matxo. Había matxo que amamantaban, tenían hijos pequeños y eran fértiles. Tal evidencia distancia a las matxo korubo de la concepción de infertilidad que subyace a la idea de «menopausia». Esta idea alberga una cierta rigidez: una especie de marco entre el período de fertilidad (sangrado) y el período de infertilidad (ausencia de sangrado). En el caso de las matxo korubo, la idea de manipulación de los fluidos corporales se vuelve fructífera, ya que permite comprender el proceso que precede y acompaña a lo que llamaríamos «menopausia».

Las matxo korubo estaban relacionadas con la característica principal de la edad más allá de la connotación biológica, una posición relacional de acumulación de conocimiento. Eran mujeres con destreza y habilidades optimizadas, evidenciadas en las tareas cotidianas: en los paseos por el bosque, en la caza y recolección y en el trato a los demás, especialmente a los niños ${ }^{25}$. La falta de fuerza o debilidad física que asociaríamos con la noción occidental de vejez traería limitaciones para pensar a las matxo korubo. Por eso, la connotación de edad aquí no puede ser meramente biológica. Las matxo eran mayores que las otras mujeres, pero también grandes, gordas y fuertes: llevaban cestos pesados, niños y jabalíes. Evidentemente, los cuerpos de las matxo sufrían transformaciones. Maya, por ejemplo, tenía episodios de crisis de dolor en ciertos momentos debido a la osteoartritis. Sin embargo, cuando no tenía dolor, realizaba todas las tareas, al igual que las demás matxo.

En los paseos por el bosque, las matxo eran las que sabían realizar lo que los korubo llaman un buen paseo (kapoe vëyla), en el sentido de «andar por el monte» ("andar no mato") ${ }^{26}$. Elegir un buen camino era elegir el mejor atajo, el mejor lugar para pasear: sin espinas, arcilla o insectos. Pero una buena caminata también consistía en optimizar la recolección y la caza, es decir, aprovechar la caminata para extraer la mayor cantidad de materia prima posible para la fabricación de artefactos y para la alimentación. Las matses sabían caminar en el bosque y también acompañaban a los hombres en la caza y recolección. Sin embargo,

25 No discutiré aquí la posición de los hombres mayores (tsusivo en korubo y darasibo, tomado de la lengua matis). Para 2020, había tres hombres considerados por los korubo como los más viejos. Lo que importa para los propósitos de esta discusión es que los tsusivo/darasibo no tenían el mismo protagonismo que las matxo entre los korubo del río Ituí.

26 Kapoe es un término korubo que se usa para referirse a los paseos por el bosque, ya sea para cazar, recolectar, pescar o acampar. Esta práctica también existe entre los matis y los matsés (kapuek, capuec). A pesar de la sedentarización en las riberas de los grandes ríos, estas expediciones continuaron realizándose como una práctica constitutiva del modo de vida de estos pueblos pano septentrionales (Erikson, 1996; Matos, 2014, p. 91). 
la madurez de las matxo se evidenciaba en la fuerza y destreza con la que realizaban todas sus tareas cotidianas.

Además de ser maestras, las matxo eran especialistas en la crianza y el cuidado, ya que generalmente tenían hijos, nietos y se casaban más de una vez. Los cuidados de las matxo abarcaban desde los mayores hasta los niños. Cortaban el pelo de todos los korubo y eran las favoritas de los niños. Con frecuencia, las matxo estaban rodeadas de niños, ya que recibían a sus nietos que residían en otras aldeas y eran llevados por sus madres para pasar tiempo con sus abuelas (txitxi matxo). Al mismo tiempo, las matxo (especialmente Maya) eran figuras de autoridad frente a las generaciones más jovenes. Las madres jóvenes amenazaban a los niños traviesos con «llamar a una matxo». Entre los adultos, esto se manifestaba en tono lúdico, pero no para los niños, que pronto se calmaban y se escondían de la inminente aproximación de una matxo.

Para comprender a Maya matxo y la posición de esta categoría de mujeres korubo, es necesario disipar las concepciones biológicas en torno al flujo sanguíneo y la vejez. A lo largo de un proceso, las matses se convierten en matxo. Alcanzar esta posición, reconocida por todos los korubo, implica una acumulación de conocimientos a lo largo de la vida. Por lo tanto, solo después de haber criado a muchas personas, caminado, recolectado, cazado y trabajado, una mujer adquirirá la destreza y el conocimiento que la caracterizará como matxo. Entonces, recibirá de los demás korubo un trato específico.

No se trata de responder aquí la distinción entre hombres y mujeres korubo, sino de escapar de una oposición dicotómica entre géneros, ya que la crítica a la oposición feminino-masculino y sus variantes (naturaleza-cultura/privadopúblico) ya fue hecha a lo largo de los años 1980 y 1990, cuando las etnografías realizadas en las tierras bajas de América del Sur y Melanesia mostraron que la transposición de estas dicotomías era infértil para la reflexión de contextos no occidentales (Overing, 1986; Strathern, 1988; Hugh-Jones, 1979; Hugh-Jones, 2001; Gow, 1989; McCallum, 1989; Belaunde, 1992).

La oposición masculino-femenino nos impediría comprender a Maya como una referencia para los korubo más allá de su actual posición de matxo. Recordemos que Maya no siempre fue una matxo. Ella se convirtió en matxo. Antes de serlo, ya figuraba como referencia entre el primer cronogrupo contactado por la FUNAI en 1996. Un referente con el poder de reunir a las personas a su alrededor y involucrarlas en su objetivo: hacer contactos con personas no indígenas para obtener herramientas de metal. Con el tiempo, Maya se convirtió en matxo, y hoy es la principal referencia para esta categoría de mujeres korubo. 


\section{CONSIDERACIONES FINALES}

Los korubo eligieron a cuatro hombres para ocupar un nuevo cargo que surgió en el contacto interétnico (cacique). Antes del contacto con los no indígenas, no había caciques entre los korubo. Tampoco se puede decir que, en el pasado, los korubo tuvieran jefes tradicionales. Alrededor de 2016, luego de los sucesivos contactos de la FUNAI con cronogrupos en diferentes ríos dentro de la tierra indígena, surgió un «nuevo cacique» entre los korubo del río Ituí. En este nuevo contexto, Maya fue reconocida por los demás, korubo y no indígenas, como una figura de autoridad. Con el tiempo, se convirtió en matxo. Se incorporó a esta categoría de mujeres mayores, hábiles en el desempeño de las tareas cotidianas y influyentes en la vida diaria de los korubo del río Ituí.

A partir de esta discusión se presentan dos posibilidades de reflexión. La primera es que Maya tenía una posición de liderazgo antes de tener contacto con personas no indígenas. La segunda es pensar que, al igual que otros pueblos de la familia lingüística pano, los korubo tenían un jefe varón y el nuevo contexto interétnico colaboró para que Maya, vinculada con este jefe fallecido, asumiera una posición de notoriedad. Si consideramos ambas posibilidades, verificamos que existen transformaciones en curso en las relaciones de género y en la forma como los korubo se presentan en el contacto interétnico.

La historia de los conflictos con los pueblos no indígenas marcó una narrativa específica sobre los korubo, en la que el estereotipo de los «caceteiros del valle del Yavarí» adquirió la dimensión de una sociedad en continua guerra. Inevitablemente, cuando pensamos en este estereotipo, nos viene a la mente la imagen de un pueblo gobernado por hombres guerreros que capturaban mujeres. Si bien podemos decir que los korubo construyen hombres guerreros, el énfasis excesivo en este estereotipo hace que el protagonismo y los roles que juegan las mujeres korubo (ya sean matxo o matses), tanto en el contexto de las guerras como en el contexto actual — es decir, en el contacto permanente con los no indígenaspase casi desapercibido.

Hablar de caciques, en el caso de korubo, es prestar atención a las figuras emergentes en el contacto interétnico. Esta nueva posición, en el futuro, puede consolidarse entre los korubo y incluso volverse similar a la concepción no indígena de «cacique» (aquel que representa una colectividad, un «pueblo», el «responsable» de la aldea). Sin embargo, esto no ha sucedido. Por un lado, al exigir voceros, seleccionar a ciertos hombres para actividades laborales remuneradas y brindar oportunidades para que estos hombres accedan a diferentes formas de 
conocimiento no indígena, el Estado alentó el surgimiento del cargo de cacique entre los korubo. Por otro lado, ante una instancia eminentemente masculina, como las instituciones indigenistas en Brasil, no hay nada más estratégico que elegir a hombres korubo para hablar con hombres no indígenas ${ }^{27}$.

El caso korubo se vuelve interesante para la discusión, ya que revela que estas figuras emergentes están en proceso de consolidación. Los caciques korubo surgieron con una función específica diferente de la concebida por el Estado. Si, para el Estado, un cacique representa una colectividad («pueblo») de la que es «responsable» y habla en nombre de; para los korubo, los caciques existen para hablar con los no indígenas, una postura activa de construir la conversación, "fazer reunião", invitar a la gente a conversar: onkeno. La construcción del cacique en la vida cotidiana de las relaciones interétnicas revela la «equivocación», característica de la comunicación entre diferentes perspectivas (Viveiros de Castro 2004), es decir, lo que constituye figuras y performances de autoridad en la cotidianidad korubo no corresponde a lo que constituye un cacique para el Estado.

En este desajuste, las instituciones estatales y indigenistas dialogaban con los caciques y hombres jóvenes, que poseían algún dominio del idioma portugués y actuaban como traductores de los korubo de río Ituí. Sin embargo, los temas discutidos en este diálogo interétnico a menudo no estaban bajo el control total de los caciques, sino que atravesaban las relaciones entre personas del mismo género, y entre géneros, vigentes en la vida cotidiana de las aldeas korubo. Es posible que, en el futuro, los caciques korubo adquieran otras funciones y más poder del que realmente tienen hoy, especialmente considerando la creciente distinción entre sus familias y las demás familias korubo. Sin embargo, lo que nos enseñan los korubo a partir del tema del surgimiento del cargo de cacique y su reelaboración es que, para dialogar con esta estructura estatal eminentemente masculina, es necesaria la creación de estrategias.

\section{REFERENCIAS}

Amorim, F. (2017). Nos tapiris korubo: uma perspectiva indigenista das tensões e distensões korubo (e Matis). Observatório dos Direitos Humanos dos Povos Indígenas Isolados e de Recente Contato/OPI. Recuperado de https://povosisolados. com/2017/06/18/nos-tapiris-korubo-uma-perspectiva-indigenista-das-tensoes-edistensoes-korubo-e-matis/. Acesso: 18/06/17.

27 Hasta marzo de 2020, el personal de la FPEVJ/FUNAI solo contaba con dos personas del género femenino. El perfil dominante era el de hombres en edad adulta. 
Arisi, B. (2007). Matis e Korubo: contato e índios isolados, relações entre povos no Vale do Javari, Amazônia [dissertação de Mestrado]. Universidade Federal de Santa Catarina.

Baines, S. (1991). «É a Funai que sabe»: a Frente de Atração Waimiri-Atroari. Museu Paraense Emílio Goeldi: Coleção Eduardo Galvão. Belém: Pará.

Belaunde, L. (1992). Gender, commensality and community among the Airo-pai of West Amazonia (Secoya, Western-Tukanoan Speaking) [PhD thesis]. University of London.

Belaunde, L. (2006). A força do pensamento, o fedor do sangue: hematologia amazônica e gênero. Revista de Antropologia, 49(1), 206-243. https://doi.org/10.1590/ S0034-77012006000100007

Belaunde, L. (2019). El recuerdo de luna: género, sangre y memoria entre los pueblos amazónicos. (tercera edición). Cusco: Ceques.

Bolívar, E. et al. (2004). Botando pereza: el yoco entre los secoyas del Putumayo. Juan Álvaro Echeverri Restrepo (comp.). Leticia: Universidad Nacional. Instituto Amazónico de Investigaciones.

Brown, M. (1993). Facing the State, Facing the World: Amazonia's Native Leaders and the New Politics of Identity. L'Homme, 33(2-4), 307-326. https://doi.org/10.3406/ hom.1993.369642

Calavia Sáez, O. (2010). La jefatura indígena, hoy. Indiana, 27, 47-62.

Carid Naveira, M. (1999). Yawanawa: da guerra à festa [dissertação de Mestrado]. Universidade Federal de Santa Catarina.

Chaumeil, J. (1990). Les nouveaux chefs...: pratiques politiques et organisations indigènes en Amazonie péruvienne. Problèmes d'Amérique Latine, 96, 93-113.

Costa, L. (2007). As faces do jaguar: parentesco, história e mitologia entre os Kanamari da Amazônia ocidental [Tese de doutorado]. Museu Nacional, Universidade Federal do Rio de Janeiro.

Coutinho Júnior, W. (2017). Gente Valente: uma Coletânea Matsés. Histórias Indígenas no Vale do Javari (1866-1974) [Tese de doutorado]. Universidade de Brasília.

D’Ávila, J. (2018). Os Kulina-Pano do Vale do Javari: Histórias, Memórias e Atuação Política [dissertação de Mestrado]. Universidade Federal do Amazonas.

Erikson, E. (1986). Altérité, tatouage et anthropofagie chez les pano: la belliqueuse quête de soi. J.S.A. LXXII.

Erikson, E. (1993). Une nebuleuse compacte: le macro-ensemble pano. L'Homme, 33(126-128), 45-58. 
Erikson, E. (1994). Los Mayoruna. En F. Santos y F. Barclay (eds.), Guía Etnográfica de la Alta Amazonía. Vol. II: Mayoruna, Uni, Yaminahua. Serie Colecciones y Documentos. Flacso: Sede Ecuador. IFEA.

Erikson, E. (1996). La griffe des aïeux: marquage du corps et démarquages ethniques chez les Matis d'Amazonie. Peeters: París. SELAF, № 358.

Erikson, E. (1999). El sello de los antepasados. Marcado del cuerpo y demarcación étnica entre los matis de la Amazonía. Lima: Instituto Francés de Estudios Andinos.

Erikson, E. (2000). Korubo: o último contato? En Instituto Socioambiental. Povos Indígenas no Brasil-96/2000, 431-433.

Erikson, E. (2002). Reflexos de si, ecos de outrem: Efeitos do contato sobre a autorepresentação Matis En Bruce Albert; Alcida Ramos (orgs.), Pacificando o branco: Cosmologias do contato no norte-Amazonico (pp. 179-204). São Paulo: Editora UNESP. https://doi.org/10.4000/books.irdeditions.24755

Fleck, D. (2013). Panoan Languages and Linguistics. Nueva York: American Museum of Natural History. https://doi.org/10.5531/sp.anth.0099

Gow, P. (1989). The perverse child: Desire in an Amazonian subsistence economy. JRAI, 24(4), 567-582. https://doi.org/10.2307/2804288

Hugh-Jones, C. (1979). From the Milk river: spatial and temporal processes in Amazonia. Cambridge: University Press. https://doi.org/10.1017/CBO9780511558030

Hugh-Jones, S. (2001). The gender of some Amazonian gifts: An experiment with an experiment. En T. Gregor y D. Tuzin (eds.), Gender in Amazonia and Melanesia: an exploration of the comparative method (pp. 245-278). Berkeley: University of California Press. https://doi.org/10.1525/california/9780520228511.003.0011

ISA. (1987/88/89/90). Javari. En Instituto Socioambiental. Povos Indígenas no Brasil, 87-90, 266-278.

Matos, B. (2014). A Visita dos Espíritos: ritual, história e transformação entre os Matses da Amazônia brasileira [tese de Doutorado]. Museu Nacional, Universidade Federal do Rio de Janeiro.

Matos, B. (2017). Caminhos e malocas: conjuntos na Amazônia Ocidental. $R @ U, 9(1)$, jan./jun., 37-60. https://doi.org/10.52426/rau.v9i1.179

Matos, B. (2019). Conflito, mediação e parentesco: as relações Matis-FUNAI-korubo no Vale do Javari. En F. Ricardo, M. Gongora (orgs.), Cercos e resistências: povos indígenas isolados na Amazônia brasileira. São Paulo: Instituto Socioambiental.

McCallum, C. (1989). Gender, personhood and social organization amongst the Cashinahua of Western Amazonia [PhD thesis]. University of London. 
McCallum, C. (2003). How Real People Are Made. Gender and Sociality in Amazonia. Oxford: Berg.

Melatti, J. (1992). Soluções das culturas panos para os enigmas do desenvolvimento corporal. En Marisa Corrêa e Roque Laraia (orgs.), Roberto Cardoso de Oliveira: homenagem (pp. 143-166). UNICAMP/IFCH.

Melatti, J. (1985). Os Patrões Marubo. Anuário Antropológico, 83, 155-198.

Oakdale, S. (2004). The Culture-Conscious Brazilian Indian. Representing and Reworking Indianness in Kayabi Political Discourse. American Ethnologist, 31(1), 60-75. https://doi.org/10.1525/ae.2004.31.1.60

Oliveira, S. (2009). Preliminares sobre a fonética e a fonologia da língua falada pelo primeiro grupo de índios Korúbo recém-contatados [dissertação de Mestrado]. Universidade de Brasília.

Oliveira, S. (2016). Relatório de atividades junto aos indígenas Korúbo. FPEVJ/ FUNAI. Relatório interno não publicado, 22.

Overing, J. (1986). Men control women? The cath 22 in the analysis of gender. International Journal of Moral and Social Studies, 1(2), 135-156.

Pereira, B. (2018). Conflitos e Contatos no Vale do Javari: relato de uma experiência de campo. En E. G. Silva Filho (org.), História e Antropologia: conexões do tempo presente. São Leopoldo: Casa Leiria.

Ramos, A. (1988). Indian Voices: Contact Experienced and Expressed. En J. D. Hill (ed.), Rethinking History and Myth: Indigenous South American Perspectives on the Past (pp. 214-234). Urbana: University of Illinois Press.

Rodrigo Octavio, C. (2015) Rios, varadouros e outros caminhos: fronteiras e territorialidades em transformação no Vale do Javari [dissertação de Mestrado]. Museu Nacional, Universidade Federal do Rio de Janeiro.

Silva, J. (2021). Korubo. En Povos Indígenas no Brasil. Instituto Socioambiental (Verbete). Recuperado de https://pib.socioambiental.org/pt/Povo:korubo

Solis, E. et al. (2013). Korubo: uma etnia entre fronteiras. Ernesto Solis, Mariana Fagundes y Luís Abramo (direção). Noctua (produção). 59 min.

Strathern, M. (1988). The gender of the gift: Problems with women and problems with society in Melanesia. Berkeley: University of California Press. https://doi. org/10.1525/california/9780520064232.001.0001

Vargas da Silva, B. (2017). Territorialidade korubo no Vale do Javari [dissertação de Mestrado]. Universidade Federal do Amazonas.

Virtanen, P. (2009). New interethnic relations and native perceptions of human-to-human relations in Brazilian Amazonia. Journal of Latin American and Caribbean Anthropology, 14, 332-354. https://doi.org/10.1111/j.1935-4940.2009.01051.x 
Viveiros de Castro, E. (2004). Perspectival Anthropology and the Method of Controlled Equivocation. Tipiti: Journal of the Society for the Anthropology of Lowland South America, 2(1), Article 1.

Viveiros de Castro, E. (2019). Nenhum povo é uma ilha. En Cercos e resistências: povos indígenas isolados na Amazônia brasileira (pp. 8-14). São Paulo: Instituto Socioambiental.

Welper, E. (2009). O mundo de João Tuxaua: (Trans)formação do povo Marubo [tese de doutorado]. Museu Nacional, Universidade Federal do Rio de Janeiro. 